\title{
Modernização trabalhista em contexto de crise econômica, política e sanitária'
}

\author{
Ricardo Lara \\ Jaime Hillesheim ${ }^{3}$
}

\begin{abstract}
Resumo
A pandemia da Covid-19 encontrou no Brasil um mercado de trabalho historicamente constituído por empregos precários, informalidade, racismo e desigualdades de gênero. Com o advento da "reforma" trabalhista (materializada essencialmente na Lei $n^{\circ} 13.467$, de 13 de julho de 2017) ampliaram-se os vínculos empregatícios por meio de novas modalidades de contratos caracterizados pela reduzida proteção social. Neste artigo, no primeiro momento, resgatamos situações históricas que determinaram a construção dos direitos trabalhistas e do mercado de trabalho no Brasil, sempre sob a égide de narrativas de modernização. No segundo momento, analisamos a tragédia social vivenciada pela classe trabalhadora após a contrarreforma trabalhista e diante da pandemia da Covid-19, cenário que apresenta tendências de crescimento das condições precárias de vida e de trabalho no Brasil.
\end{abstract}

\section{Palavras-Chaves \\ Brasil; Modernização; Pandemia; Contrarreforma trabalhista.}

Labor modernization in the context of economic, political and health crisis

\begin{abstract}
The Covid-19 found in Brazil a job market historically constituted by precarious jobs, informality, racism and gender inequalities. With the advent of labor "reform" (materialized essentially in Law N. 13,467, of July 13, 2017), employment bonds were expanded through new types of contracts characterized by the very low social protection. In this article, in the first moment, we recover historical situations that determined the construction of labor rights and the labor market in Brazil, always under the umbrella of modernization narratives. In the second step, we analyze the social tragedy experienced by the working class after the labor counter-reform and in the face of the Covid-19, a scenario that presents trends of growth in the precarious living and working conditions in Brazil.
\end{abstract}

\section{Keywords}

Brazil; Modernization; Pandemic; Labor reform.

Artigo recebido em junho 2020

Artigo aprovado em agosto de 2020 


\section{Introdução}

A Organização Mundial da Saúde (OMS) declarou, em 30 de janeiro de 2020, que o surto da doença Covid-19, causada pelo novo coronavírus (SARS-CoV-2), constitui emergência de saúde pública de importância internacional, o mais alto nível de alerta da OMS, conforme previsto no Regulamento Sanitário Internacional. Em 11 de março de 2020, a Covid-19 foi caracterizada pela OMS como uma pandemia.

Entre as análises críticas (CHUANG, 2020; HAYS, 2015; WALLACE, 2016; PAIM e ALONSO, 2020) que investigam as origens sócio-históricas das pandemias e, por conseguinte, da Covid-19, temos importantes evidências científicas quando consideramos o modelo agrícola hegemônico das relações sociais de produção de capital, e não somente e de forma isolada o mercado de animais vivos da cidade de Wuhan 4 . Para compreensão de pandemias como a Covid-19, torna-se necessário considerar as seguintes questões: a humanidade está colhendo os resultados das opções de produção de alimentos e uso intensivo de agrotóxicos; a produção intensiva e a criação de animais (fazendas industriais) proporcionam condições perfeitas para o surgimento de cepas virais altamente patogênicas; essa maneira de produção ativa de forma absoluta as mutações do sistema climático global e substratos microbiológicos da vida; as condições de habitação e insalubridade proporcionam, com facilidade, a disseminação de doenças que se tornam pandemias no mundo globalizado em que vivemos. É evidente, conforme já indicamos, que essas questões não podem ser analisadas isoladamente do modelo de produção hegemônico capitalista, em especial o denominado agrobusiness ${ }^{5}$.

Pelas características estruturais do modo de produção capitalista, assumimos como pressuposto que as pandemias, catastróficas para a humanidade, são produtos desta mesma estrutura de produção. As consequências econômicas e sociais ainda estão em curso, mas uma das poucas certezas é que a classe trabalhadora e os segmentos sociais mais vulneráveis de todos os continentes serão profundamente atingi- 
dos. As condições de vida sofrerão retrocessos inimagináveis se alguma alternativa política substantiva não for produzida em curto prazo. O vírus pode ser policlassista e contaminar indivíduos pobres e ricos, mas os resultados já indicam que as classes subalternas são as mais atingidas. Os desempregados, favelados, moradores de rua, comunidades quilombolas, tribos indígenas e trabalhadores informais compõem o contingente mais atingido pela pandemia da Covid-19 no Brasil.

Para piorar a situação, a pandemia encontrou um dos piores e mais autoritários governos federais da história do Brasil. Autoritarismo, negacionismo, desprezo pelas orientações das organizações e profissionais da saúde estiveram presentes nas ações de Bolsonaro e de seus seguidores desde o inicio da Covid-19 no País. Os conflitos ideológicos e políticos intensificaram em 2020, principalmente em razão de investigações que apertavam os cercos ao presidente e seus apoiadores, seja pela produção de fake News, ou pelas denúncias de tentativas de interferência na polícia federal para atender interesses privados escusos.

O mercado de trabalho brasileiro estava imerso em uma tragédia que se tornara ainda maior em virtude da aprovação da contrarreforma trabalhista que, ao contrário de gerar empregos com proteção social, produziu relações e condições de trabalho apoiados na informalidade, subutilização, subemprego e na ideologia do empreendedorismo. A particularidade brasileira não apresentava boas perspectivas para os trabalhadores e trabalhadoras.

Portanto, neste artigo, objetivamos problematizar os impactos deletérios da contrarreforma trabalhista para a classe trabalhadora diante da pandemia da Covid-19. Para isso, resgatamos situações históricas que denominamos de modernizações, principalmente na (des)construção dos direitos trabalhistas e do mercado de trabalho no Brasil. E, em seguida, analisamos a crise vivenciada pela classe trabalhadora após a contrarreforma trabalhista que se encontrou com a pandemia e acentuou ainda mais as precárias condições de vida no Brasil. 


\section{As modernizações e o trabalho na formação social brasileira}

As relações e condições de trabalho no Brasil foram constituídas em uma formação socioeconômica em que a informalidade, o racismo, a restrição aos direitos sociais sempre estiveram presentes no mercado de trabalho. Podemos afirmar que a precarização do trabalho é uma situação permanente e histórica no Brasil. Na emergência da modernização que criou o mercado de trabalho assalariado, nas últimas décadas do século $X I X^{7}$ e início do século $X X$, o Estado, a aristocracia rural e a burguesia industrial ${ }^{8}$ fizeram opção pelo trabalhador imigrante europeu em detrimento do aqui já existente africano escravizado (que se tornará trabalhador assalariado) e/ou mesmo do trabalhador nacional. A análise da formação original do mercado de trabalho assalariado no Brasil apresenta indicativos de uma modernização racista e segregacionista, que acompanha e manifesta-se até hoje na sociedade brasileira, encoberta pela ideia da vigência de uma democracia racial.

Ao analisarmos as consequências da abolição para o ex-escravo na produção cafeeira, principal produto do Brasil na época, notamos que a partir de 1888 estruturou-se uma nova inserção regional de trabaIhadores no plantio e cultivo do café no sudeste do país. Os imigrantes dirigiram-se para as principais regiões produtoras e aos ex-escravos restavam as regiões mais decadentes economicamente (KOWARICK, 2019). A classe trabalhadora assalariada no Brasil foi formada, originalmente, por um conjunto de determinações que congregam a colonização, o trabalho cativo, o tráfico negreiro, a escravização e a imigração. Essas determinações históricas não podem ser desconsideradas ao nos aventurarmos na análise da formação social brasileira e seu contingente disponivel de força de trabalho.

As poucas conquistas de direitos trabalhistas e sociais que a classe trabalhadora alcançou na primeira metade do século $X X$ foram permeadas de corporativismos e intervenção estatal. Evidente que lutas de classes e resistências ocorreram, foram décadas de conflitos classistas para os trabalhadores e trabalhadoras conquistarem legislações 
sociais que oferecessem proteção social, mas quando a classe trabaIhadora estava em condições de atingir seus objetivos que poderiam resultar em genuínas conquistas históricas, emergem Estados autoritários gestados por golpes seguidos de ditaduras que interditam possíveis avanços na arena da emancipação política, ou seja, dos ganhos possíveis proporcionados pela democracia burguesa?

Na década de 1930 e 1940, com o Estado Novo, o cenário político e econômico alimentado pelo crescimento do proletariado urbano e industrial ${ }^{10}$ possibilitaram avanços aos direitos trabalhistas, mas, em contrapartida, a autonomia da classe trabalhadora foi roubada, como bem analisa Paranhos (2007). A legislação social do trabalho e a legislação sindical foram incorporadas ao discurso oficial do Estado que minimizou a autonomia e controlou o movimento operário. A despeito disso, resistências foram produzidas na história do trabalho e dos conflitos sociais no Brasil, mesmo com largo controle do Estado e de seguidas contrarrevoluções e ditaduras. O movimento sindical, operário e social brasileiro obtiveram protagonismos importantes, seja na conquista da Consolidação das Leis do Trabalho de 1943, na construção dos movimentos campesinos de luta pela reforma agrária, de movimentos urbanos que ainda hoje reivindicam moradias, mas sempre é pertinente recordar que a cada avanço que proporcionava mínimas garantias de vida para a população pobre e trabalhadora, a resposta foi de contrarrevoluções preventivas, modernização controlada, em que a modernidade dos direitos sociais das conquistas da revolução burguesa não se completava na realidade brasileira"1.

Em 1964, com o golpe e a implantação da ditadura civil-militar, os direitos sociais sofreram profundos retrocessos. Foi o momento da modernização autoritária por meio do emprego do poder das forças armadas (FERNANDES, 2009). O golpe de abril, apoiado pelo imperialismo norte-americano ${ }^{12}$, pelos setores conservadores da alta hierarquia da igreja católica, pela burguesia internacional e nacional (industrial e financeira, os grandes proprietários de terras), conte- 
ve o avanço das forças populares que vinham num crescente nível de organização e mobilização em torno das lutas pelas reformas de base. João Goulart pretendia um governo minimamente voltado para a justiça social e a soberania nacional. Sua política de valorização dos direitos trabalhistas, de defesa das reformas de base - agrária, tributária, urbana, educacional e eleitoral - e de independência nas relações exteriores, juntamente com a tentativa de limitar a remessa dos lucros do capital estrangeiro para fora do país, desagradou os interesses da burguesia brasileira associada ao capital imperialista. Tais reformas foram ideologicamente vinculadas aos preceitos comunistas que seriam implementados pela extrema esquerda que se opunha aos valores da família e da propriedade privada. Hoje, analogamente, qualquer pessoa que faça críticas ao governo federal e defenda a manutenção de direitos sociais é ideologicamente alinhada aos "esquerdistas" corruptos que estão contra o "povo".

Os direitos humanos foram os primeiros a serem banidos do Brasil com a ditadura civil-militar. Torturas, assassinatos, prisões e exílios se intensificaram ao longo da radicalização da autocracia burguesa que se alicerçava no poder com os militares. Os direitos trabalhistas foram atacados com o fim da estabilidade no emprego aos trabalhadores que conquistavam essa possibilidade após dez anos de trabalho na mesma empresa. A substituição da estabilidade no emprego ocorreu com a criação do Fundo de Garantia por Tempo de Serviço (FGTS), instituído pela Lei n. 5.107, de 1966, que acabou estimulando ainda mais a rotatividade no mercado de trabalho, uma característica muito presente da classe trabalhadora brasileira até hoje.

Durante a ditadura civil-militar, ao final de cada balanço econômico, em especial do período conhecido como "milagre econômico" (1968-1973), anos que buscava principalmente a ascensão das empresas multinacionais e da elite privilegiada do país, o governo militar e a burguesia vangloriavam-se pelos números, pelo "clima de calma e tranquilidade" que diziam existir no País e, portanto, pelas altas taxas 
de lucros obtidas pela intensa exploração da força de trabalho. O Brasil era um país de aparências, onde só eram observados e levados em consideração os dados da economia industrial pela ótica da burguesia, deixando de lado a análise socioeconômica de quem realizava a real produção interna do País, a massa de trabalhadores assalariados, que se encontrava mais da metade recebendo menos de um salário mínimo, e em péssimas condições sociais e de trabalho, sendo o Brasil, na época, um dos primeiros países em indicadores como subnutrição, mortalidade infantil e acidentes de trabalho (HABERT, 1992).

Os ataques aos direitos trabalhistas caminharam pari passu às conjunturas econômicas e políticas da sociedade brasileira. Em especial a partir dos anos de 1960, com a contrarrevolução preventiva (ditadura civil-militar), a classe trabalhadora nacional entrou numa conjuntura de constantes e contínuas retiradas de direitos sociais. As principais medidas resultaram no arrocho salarial, questão relacionada aos ataques às organizações representativas de classe mais combativas e às restrições ao direito de greve. Contudo, em fıns dos anos 1970, o movimento sindical toma novo fôlego no $A B C$ paulista, potencializando a retomada do sindicalismo classista. Com o ressurgimento do movimento sindical combativo, principalmente em São Bernardo do Campo, na região da Grande São Paulo, onde se desenvolveu o parque automobilístico brasileiro, forma-se uma nova classe operária que passa a contestar o modelo econômico concentrador de renda da ditadura civil-militar e a lutar por liberdades democráticas. Os sindicalistas exigiram autonomia e liberdade sindical, fim do arrocho salarial e melhores condições de vida. Essa efervescência política propiciava, assim, no refluxo da ditadura, um novo avanço dos trabalhadores entre os anos de 1979 e 1989. Esse avanço ocorre em duas fases: uma social, consubstanciada nas lutas pela terra, pelas greves massivas de sindicatos, e lutas urbanas entre 1979-1985; e outra subsequente marcada pelo avanço político e econômico (1986-1989), com progressos na legislação social através da Constituição Federal de 1988 (ANTUNES, 1991). 
Na década de 1990, já sob a égide do neoliberalismo, as reivindicações da classe trabalhadora foram defensivas e marcadas por pautas contra os processos de flexibilização das leis trabalhistas. Parte importante do movimento sindical passou a assumir uma postura de cooperação com o capital, com práticas assentadas na perspectiva da conciliação de interesses, afastando-se daquele sindicalismo classista. A modernização trabalhista que se consolidou em 2017 já estava presente no ideário da burguesia industrial13 desde então. As contrarreformas nas políticas sociais (retiradas de direitos históricos, como no caso da previdência) e a privatização do patrimônio público foram as principais causas da defensiva do movimento sindical e social.

Nos anos 2000, com a vitória do Partido dos Trabalhadores (PT) nas eleições de 2002 para o governo federal, colocaram-se, no horizonte das classes populares, esperanças para combater as desigualdades estruturais da sociedade brasileira. Entre 2004 e 2012, os programas sociais voltados para os mais empobrecidos obtiveram êxitos em razão de uma conjuntura econômica favorável às exportações e a inserção internacional do Brasil nos circuitos da produção mundial, em especial com o avanço da exportação de commodities ancorada no agronegócio. A retomada do crescimento econômico, a partir de 2004, possibilitou ao Brasil a expansão do Produto Interno Bruto (PIB) com melhoria na distribuição de renda, incremento real do salário mínimo e ampliação de empregos (ainda que marcados por condições e relações de trabalho precárias), mas, em contrapartida, tivemos a manutenção da política que combinou rigoroso equilíbrio fiscal, nos moldes preconizados pelo Fundo Monetário Internacional (FMI), com políticas sociais compensatórias para aliviar a pobreza. A política adotada pelo Ministério da Economia, nos governos de 2003 a 2016, deu continuidade à política macroeconômica conservadora com base nos mesmos pressupostos neoliberais presentes no Brasil desde o início dos anos 1990, pois atenuou a primazia dos financistas em favor de maior equilíbrio com o agronegócio e com os exportadores industriais, 
e "com esta variante de social-liberalismo os principais grupos econômicos mantiveram altas taxas de rentabilidade" à custa da precarização da vida da maioria da população (KATZ, 2012, p. 89).

Ao observamos a economia e os parcos avanços no Brasil a partir dos anos 2000, com exceção de alguns progressos em políticas do sistema de proteção social, notamos que a prioridade foi a destinação de recursos financeiros para o grande capital, por meio do pagamento da dívida pública, em prejuízo da seguridade social e dos direitos sociais universais. Em 2014, a crise econômica atinge o Brasil juntamente com as denúncias de corrupção de importantes quadros do governo federal e de políticos de demais partidos que historicamente sempre estiveram presentes em Brasília nas bases de apoio dos diversos governos federais. O caminho para o impeachment de Dilma Rousseff foi a saída encontrada por muitos políticos corruptos tentarem obstruir a Operação Lava Jato, como também a conciliação de classe proposta pelo PT não era mais viável para segmentos da burguesia nacional.

A crise política, com as denúncias dos casos de corrupção envolvendo empreiteiras e empresas estatais, coexistiu com a crise econômica. É nesse contexto que os empresários e representantes da burguesia nacional pressionaram o legislativo e o executivo com a pauta da modernização trabalhista, que na verdade constituiu-se em permanente regressão dos direitos conquistados historicamente. Os direitos trabaIhistas, que ao longo da história do Brasil sempre foram atacados e flexibilizados, tornaram-se os principais alvos perseguidos pelos patrões com a concepção de que o alto custo da força de trabalho, elevado número de processos trabalhistas e uma legislação arcaica eram os principais entraves à retomada do crescimento econômico ${ }^{14}$.

Após o golpe na democracia brasileira e a consolidação do impeachment, os empresários avançaram com o objetivo de "modernizar" direitos trabalhistas e consolidar as contrarreformas, evidenciando de forma explícita as práticas predatórias da burguesia brasileira. É nesse cenário ideológico que a Lei nº 13.467 (contrarre- 
forma trabalhista) foi aprovada em julho de 2017, tendo como principais bases a supremacia das negociações entre trabalhadores e empregadores sobre as normas trabalhistas, a expansão das atividades terceirizadas, a amplitude dos contratos de trabalho e jornadas de trabalhos ajustáveis ao ritmo do mercado, os limites ao acesso e atuação da Justiça do Trabalho e, ainda mais, o ataque às formas de financiamento dos sindicatos.

É importante demarcar, mais uma vez, que a contrarreforma trabalhista foi aprovada no contexto de um golpe político e institucional e sem debates abertos com os sindicados dos trabalhadores e o conjunto da sociedade civil brasileira. O curto período de tramitação das propostas legislativas no Congresso Nacional revelou a pressa da burguesia, que desde os anos 1960, tinha como prioridade a flexibilização irrestrita das relações de trabalho. A Lei 13.467, materialização mais proeminente da contrarreforma, entrou em vigor em 11 de novembro de 2017, corroborando um contexto de regressão de direitos sociais, privatizações e interferência mínima do Estado na reprodução social.

\section{A narrativa da modernização trabalhista no Brasil: encobrimento do caráter regressivo das inovações legislativas e o avanço sobre os direitos laborais no contexto da crise sanitária}

A contrarreforma trabalhista, baseada na ideologia da modernização cuja essência é regressiva, alterou mais de 117 artigos da Consolidação das Leis do Trabalho (CLT), determinando a prevalência das negociações contratuais sobre o legislado. $O$ "negociado" pode até ser uma possibilidade para ações coletivas dos trabalhadores amparados por seus respectivos sindicatos, desde que sejam respeitados os direitos trabalhistas garantidos em lei ou ampliados, mas, com a contrarreforma trabalhista o que ocorreu foi mais uma tentativa de reduzir a proteção social ao trabalhador. O Brasil foi construído sobre as bases de modernizações conservadoras, sempre de acordo com os novos processos sócio-históricos nos quais a exploração da força de traba- 
Iho era alocada também sobre novos patamares, aprofundando ainda mais as péssimas condições de vida da população.

As medidas de austeridade em âmbito mundial nas últimas duas décadas promoveram significativos regressos políticos e sociais, consubstanciando-se em verdadeiras derrotas às classes trabalhadoras e aos direitos humanos. Seja sob a ideologia da austeridade, do novo regime fiscal ou da modernização trabalhista, o que está em questão no que conceituamos como modernização regressiva é a possibilidade de a produção capitalista manter as taxas de lucro e explorar força de trabaIho sem limitações impostas por legislações sociais de proteção ao trabalhador, com possibilidade de regredir às condições e relações de trabalho pretéritas, muito próximas das existentes no início do século XIX.

No Brasil, a chamada modernização trabalhista tem essência regressiva, pois se consubstanciou no mesmo contexto histórico das políticas de ajuste fiscal, principalmente pela redução de investimento do governo federal em políticas públicas. No plano da conformação ideológica há mais de quatro décadas destacam-se as formulações que deram apoio às contrarreformas, a ideologia de desresponsabilização do Estado, o desfinancimento público das políticas sociais e, paralelamente, a subserviência dessa estrutura jurídico-política ao padrão de acumulação capitalista rentista imposto pelas agências internacionais. As cartilhas dos organismos internacionais (destacando-se os relatórios do Fundo Monetário Internacional - FMI, e o do Banco Mundial) preconizavam, em um primeiro momento, que o Estado deveria modernizar-se, acabar com as velhas "estruturas deficitárias" e de "caráter paternalista", empurrando as responsabilidades sociais ao "dinâmico e equilibrado" universo do mercado (BEHRING, 2010, p. 65).

Após pouco mais de dois anos da contrarreforma trabalhista as estatísticas do mercado de trabalho comprovam que os objetivos defendidos $^{15}$ não foram atingidos. As promessas de geração de novos empregos não foram cumpridas. A pandemia da Covid-19 encontrou uma classe trabalhadora inserida em condições e relações de trabalho já 
muito aviltantes. O número de desempregados aumentou, o trabalho informal cresceu e, em síntese, a nova legislação contribuiu tão somente para consolidar a histórica precarização do trabalho no Brasil. Ainda no mesmo ano da contrarreforma trabalhista, o número de desempregados aproximava-se de 13 milhões, sem levar em conta os desalentados, o que somaria um desemprego total de 26,6 milhões (FILGUEIRAS, 2019, p. 35). Esses dados foram utilizados pelos ideólogos da contrarreforma trabalhista para justificar sua necessidade, inclusive. A promessa de Henrique Meirelles, à época Ministro da Fazenda, era que a "reforma" deveria gerar mais de 6 milhões de empregos, ou seja, abarcava quase $50 \%$ dos desempregados. Afirmavam veementemente que, aprovada a "reforma trabalhista", os empresários teriam mais oportunidades de investimento nas empresas e os trabalhadores mais empregos. Isso não aconteceu e, mais, nos anos subsequentes à contrarreforma os índices de desemprego mantiveram-se em patamares muito similares e os ataques a outros direitos sociais continuaram.

O certo é que a burguesia conseguiu mais garantias jurídicas, e os trabalhadores, mais empregos temporários, intermitentes e menos proteção social. Os dados do mercado de trabalho, no momento em que a nova legislação trabalhista completava 18 meses, indicava que 15,4\% dos postos de trabalho criados eram para trabalhos intermitentes, cerca de 101,599 vagas. Esse número indica que do total de vagas criadas (660.390 entre novembro de 2017 e julho de 2019), quase uma em cada seis foi para a modalidade de contrato intermitente. Além disso, cerca de 28,1 milhões de pessoas estavam sem emprego (IBCE, 2019) ${ }^{16}$.

Nos primeiros meses de 2020, os números do mercado de trabalho continuavam desestimulantes para os trabalhadores e trabalhadoras do Brasil. As contrarreformas nas políticas sociais fizeram emergir cenários de instabilidade social que atingiram desmedidamente a reprodução da vida da maioria da população, em especial daquelas que sobrevivem da venda de suas próprias forças de trabalho. A taxa de desocupação no Brasil, no primeiro trimestre de 2020, atingia 12,2\%, 
cerca de 12,85 milhões de desempregados. A informalidade atingia 39,9\% da população ocupada, ou seja, 36,8 milhões de trabalhadores. Os desalentados (desempregados que por uma razão ou outra não procuraram emprego) eram 4,7 milhões. A taxa de subutilização (pessoas desocupadas e subocupadas por insuficiência de horas trabalhadas) chegou a 24,4 milhões de pessoas. Esses dados referem-se ao total de 105,1 milhões de pessoas, contingente da força de trabalho (pessoas ocupadas e desocupadas), no trimestre de janeiro a março de 2020. (PNAD/IBGE, 2020). É nesse contexto de crise econômica, agravada por uma crise política gerada pelas ações e/ou inércia do (des)governo Bolsonaro, que o Brasil enfrenta também uma crise sanitária decorrente da pandemia da Covid-19.

O mercado de trabalho do Brasil apresenta nesse período dados alarmantes, mas ainda não revelavam a totalidade da tragédia da classe trabalhadora. As jornadas de trabalho dos trabalhadores informais (36,8 milhões) chegavam, em alguns casos, a 14 horas ou mais por dia, muitos eram trabalhadores dos mais diversos aplicativos como Uber, Rappi, ifood, ou trabalhadores que exerciam as mais diversas atividades para sobreviverem como ambulantes, camelôs, autônomos, catadores de material reciclável, feirantes. Muitos desses trabalhadores pleitearam o auxílio emergencial em busca dos $\mathrm{R} \$ 600,00^{17}$. Cabe recordar que originalmente a proposta do executivo federal era de que tal benefício fosse de apenas $\mathrm{R} \$ 200,00$.

Os microempreendedores individuais também foram os trabalhadores intensamente atingidos pela pandemia e muitos tiveram grandes dificuldades no acesso aos programas do governo federal ${ }^{18}$. $\mathrm{O}$ empreendedorismo como alternativa ao trabalho regulado demonstrou seus limites na emergência da pandemia.

Para salvar o emprego dos trabalhadores que obtinham trabalho formal, a primeira atitude do executivo federal foi a elaboração da Medida Provisória 927, que permitia a suspensão dos contratos de trabaIho por quatro meses sem pagamento dos salários, mas a barbárie foi 
tamanha, que após reações do conjunto da sociedade organizada, foi elaborada a Medida Provisória 936 com a denominação de Programa Emergencial de Manutenção de Emprego e Renda. Esta permitiu a redução da jornada de trabalho com percentuais que podiam ser, a princípio, de $25 \%$, 50\% ou $70 \%$, com correspondente desconto nos salários, além da autorização para a suspensão do contrato de trabaIho (redução de $100 \%$ da jornada e do salário). O consequente corte nos salários seria proporcionalmente compensado de acordo com o valor do seguro-desemprego. A Medida Provisória 936 também alterou diversas regras da legislação trabalhista e aprofundou a contrarreforma trabalhista (aprofundando seu caráter regressivo). Por exemplo, acordos individuais celebrados no período de calamidade pública prevaleceram sobre os instrumentos legais em vigor (acordado se sobrepondo ao legislado). Os principais objetos desses acordos foram: permissão do trabalho remoto (teletrabalho, home office); concessão de férias coletivas com aviso antecedente de apenas 48 horas; antecipação de férias individuais e de feriados; regime especial de compensação (banco de horas); suspensão de exigências administrativas em segurança e saúde do trabalhador (MATTEI; HEINEN, 2020, p.12).

Outro fator importante a ser considerado nesse contexto e que repercute diretamente na reprodução social da classe trabalhadora e da sociedade como um todo, diz respeito ao endividamento. O endividamento da população é um elemento fundamental para dinâmica financeira rentista. Apesar de o crédito cedido aos trabalhadores serem modestos, é possível observar esse impacto no contexto da pandemia. O número de famílias com dívidas em cheque pré-datado, cartão de crédito, cheque especial, carnê de loja, empréstimo pessoal, prestação de carro e seguro bateu novo recorde em abril de 2020, alcançando 66,6\%, o maior percentual desde janeiro de 2010, início da realização da Pesquisa de Endividamento e Inadimplência do Consumidor (CNC, 2020). O endividamento para a classe trabalhadora significa sobretrabalho, ou seja, mais tempo de trabalho que será destinado a pagar suas 
dívidas, um saque do tempo de trabalho que se converte em salário. A outra parte é a mais-valia que se destina diretamente ao comprador da força de trabalho, ao burguês. Assim, o rentismo, em todas as suas expressões, aproveitou a pandemia para maximalizar seus lucros.

As desigualdades de salários, habitação e todas as demais necessidades básicas de reprodução social fazem do Brasil um dos países com as piores condições de vida para a maioria da população. A pandemia da Covid-19 escancarou as misérias do País, onde os investimentos em políticas públicas (saúde, educação, assistência social) historicamente foram insuficientes para o número de pessoas que delas precisam e deveriam ter acesso como direito social. Se os ataques aos direitos trabalhistas vêm de longa data e atrelados a propostas de modernizações conservadoras frequentes, também os recursos destinados à habitação e saneamento básico foram insuficientes e compõem a dimensão estrutural da "questão social" brasileira. Na maior parte dos municípios do Brasil, mais de $50 \%$ da população não tem esgoto coletado. Aproximadamente 6,1 milhões de domicílios não contavam, em 2019, com água diariamente, cerca de 18,4 milhões de brasileiros. Mais de 13 milhões de pessoas viviam em favelas e bairros pobres das principais capitais do Brasil (BARREIRA, 2020). A Covid-19 produziu mais vítimas nas favelas. As periferias das cidades com os insuficientes serviços sanitários acabaram escancarando as situações crônicas do Brasil, conforme se pode constatar pelos indicadores da pandemia. A Covid-19 exige mais do que políticas para salvar a economia e poucos empregos, serão necessárias verdadeiras políticas de saúde, habitação e vigilância sanitária, questões que não constituíram pauta prioritária dos governos, em todas as esferas.

A implementação de políticas públicas que possam atender às necessidades da classe trabalhadora, agravadas pela pandemia, contudo, não estava e nem está no horizonte dos governos, preocupados, de um lado, com a destinação de recursos para salvaguardar os interesses econômicos e, de outro, com a observância 
das regras dos organismos internacionais que impõem ajustes fiscais permanentes. No curso da pandemia, o governo federal lançou o Programa Federativo de Enfrentamento ao Coronavírus. A partir dele, liberou recursos para estados e municípios, e parte desses recursos era destinada exclusivamente para as áreas de saúde pública e assistência social e parte para livre aplicação. Aos estados foram liberados 7 bilhões de reais para a saúde e assistência social e 30 bilhões para uso discricionário, desde que aplicados em ações de enfrentamento à pandemia. Para os municípios foram liberados 3 bilhões de reais para investimentos em saúde e assistência social e 20 bilhões para livre aplicação ${ }^{19}$. Esses valores totalizam 60 biIhões de reais. Por outro lado, sob o argumento de tentar socorrer a economia e os empregos em face dos efeitos do coronavírus, o governo federal, por meio do Banco Central, destinou 1,2 trilhões de reais no Sistema Financeiro Nacional (SFN), pretendendo aumentar a liquidez dos bancos ${ }^{20}$. Numa análise comparativa, constata-se que o valor destinado para o atendimento da população em face da pandemia corresponde a $5 \%$ do que foi destinado para socorrer o grande capital, especialmente o capital financeiro.

Enquanto isso, os trabalhadores que permaneceram em suas atividades durante a pandemia, em vários casos, encontraram acesso limitado aos equipamentos de proteção individual, como também ficaram expostos à contaminação no translado ao local de trabalho. Os profissionais da saúde e os que atuavam em atividades de abate de animais, limpeza e higienização, agricultura, abastecimento (supermercados), logística, assistência social, funerárias não pararam suas jornadas de trabalho, pelo contrário, intensificam-nas ${ }^{21}$, colocando não somente suas vidas em risco, mas também as das pessoas de seu convívio mais direto em virtude da possibilidade de contaminação e transmissão do vírus.

Durante a pandemia um número significativo de profissionais continuaram suas atividades por meio do teletrabalho. Essa modalidade de uso da força de trabalho encontrou um momento pro- 
pício para sua ampliação, ainda que nos últimos anos, no Brasil, o teletrabalho já vinha sendo bastante usado. Do ponto de vista do capital, essa modalidade de trabalho permite maior flexibilização e produtividade, haja vista que o não acompanhamento do que o trabalhador está fazendo durante sua jornada torna-se dispensável. A preocupação passa a ser o acompanhamento da tarefa e da entrega. Do ponto de vista do trabalhador, o teletrabalho implica a não desconexão entre as atividades do trabalho e as da vida privada. 0 tempo do trabalho avança para o chamado tempo potencialmente livre. Ademais, como precisa responder às tarefas e prazos definidos pelo empregador, o trabalhador comumente precisará também estender sua jornada. O teletrabalho geralmente é realizado no espaço do domicílio, o que de certo modo faz dissipar a percepção do trabalhador de que ele está trabalhando 22 .

Uma das áreas em que mais se evidenciou o uso da força de trabalho por meio do teletrabalho ou trabalho remoto foi a educação. Nesse setor, os profissionais foram forçados, principalmente pelas instituições de ensino privado, a desenvolverem suas práticas pedagógicas (originalmente presencias) na modalidade de ensino a distância (EAD), geralmente denominado de ensino remoto. Isso acarretou mais sofrimento mental ${ }^{23}$ para esses profissionais que não estavam preparados para o desenvolvimento dessa modalidade de ensino, adaptado de qualquer jeito para dar consecução a propostas pedagógicas que não haviam sido estruturadas para serem implementadas por meio não presencial. No âmbito das unidades familiares, especialmente no interior da classe trabalhadora e periférica, a falta de estrutura para dar continuidade às atividades educacionais (equipamento adequado, acesso à rede mundial de computadores, qualidade de conexão, etc.), somada a um conjunto de outras consequências da pandemia (redução da renda, perda de emprego, adoecimento, conflitos gerados pelo estresse do isolamento social, etc.) e às condições precárias de vida (falta de 
saneamento, submoradias, não acesso ao direito à alimentação, etc.) provocaram inúmeros outros prejuízos objetivos e subjetivos. A despeito disso ou em virtude disso, o contexto da pandemia foi compreendido como uma oportunidade para o mercado educacional, cujo crescimento em 2019 já tinha sido bastante significativo ${ }^{24}$. Também o setor público da educação foi identificado como potencializador das oportunidades para o mercado de tecnologias de informação e comunicação, fazendo avançar em direção às metas de expansão desse mercado.

No Brasil e no mundo os trabalhadores têm enfrentado processos intensos de desmonte do acervo de direitos conquistados historicamente. Além da crise econômica que evidencia cada vez mais os limites do capital, as condições de vida e de trabalho são ainda mais precarizadas em face da crise sanitária decorrente da pandemia da Covid-19. De acordo com a Organização Internacional do Trabalho (OIT), os prospectos indicam o aumento do trabalho infantil e a precarização do labor dos trabalhadores domésticos na América Latina e Caribe. Além disso, para o ano de 2020, a OIT indica que cerca de 27 milhões de pessoas, especialmente aquelas que integram os segmentos de trabalhadores mais pobres, mulheres, jovens e imigrantes ficarão desempregadas ${ }^{25}$.

\section{Considerações finais}

A Covid-19 plantou muitas incertezas no mundo do trabalho. Não sabemos quanto tempo a pandemia vai durar. Pode ser meses ou até mesmo anos. A certeza que já temos é que as classes subalternas e vulneráveis são as mais atingidas. O desemprego começa a subir em proporções homéricas. Os indicadores já ultrapassam as marcas da crise da década de 1930. Até junho de 2020, foram perdidos 42,6 milhões de postos de trabalho nos Estados Unidos. No Brasil, que já apresentava péssimo desempenho do mercado de trabalho, a situação foi agravada; até maio deste ano 1.100 mi- 
Ihões de trabalhadores perderam seus empregos, no mundo foram 305 milhões de empregos perdidos, destes 13,2\% são da América Latina e Caribe (OIT, 2020).

A pandemia acentuou a crise econômica que coexistia com a crise ecológica (aquecimento global, desmatamentos, poluição), gerando uma crise sanitária em proporções globais e inédita na história mundial. A produção destrutiva intensificou sua ação e colocou em xeque o direito à vida. Agora, mais do que nunca, serão necessárias políticas de seguridade social, que ofereçam saúde, emprego e assistência social a milhões de pessoas que ingressarão na pobreza absoluta.

De acordo com a Comissão Econômica para América Latina e Caribe (CEPAL), a previsão é que a atividade econômica da região se contrairá em 5,3\% em 2020 (OIT, 2020). Analistas indicam retração de 6,25 \% do Produto Interno Bruto do Brasil. À medida que a pandemia se prolonga os dados negativos da economia serão ainda maiores. Uma questão é certa, a recessão será global e demandará reinvenções substantivas para que a humanidade tenha futuro. Esses dados serão postos à prova nos próximos meses. A certeza que já temos é de que a pobreza e a insegurança no emprego para a maioria da população são certas e constantes. A crise social impacta severamente as mulheres e a população negra. As mulheres em razão de serem a maioria no trabalho doméstico e a minoria nos serviços considerados essenciais. A população negra por, historicamente, ter maior participação na informalidade e nos chamados trabalhos precários sem proteção social.

Portanto, se a classe trabalhadora e suas organizações políticas (movimentos sindicais e sociais) que representam a maioria da população não apresentarem um autêntico e alternativo projeto de sociedade que a revolucione substancialmente, corre-se o risco de a vida pós-pandemia ser ainda pior do que antes, com o aumento da pobreza absoluta, conflitos sociais e mais miséria ideológica. Chegou a hora de uma modernização progressiva com traços revolucionários! 


\section{Referências}

ANTUNES, R. O Novo Sindicalismo. São Paulo: Brasil Urgente, 1991.

BARREIRA, G. Favelas do Rio somam mais mortes por Covid-19 do que 15 estados do Brasil. Disponível em: https://g1.globo.com/rj/rio-de-janeiro/noticia/2020/05/21/favelas-do-rio-somam-mais-mortes-por-covid-19-do-que-15-estados-do-brasil.ghtml. Acesso em: 22 maio 2020.

BEHRING, E. R. Crise do capital, fundo público e valor. In: BOSCHETTI, Ivanete; BEHRING, E. R; SANTOS, S. M. M.; MIOTO, R. C. T. (Orgs.). Capitalismo em crise: Política social e direitos. São Paulo, Cortez, 2010.

BRASIL. Lei n. ${ }^{\circ} 13.429$, de 31 de março de 2017a. Altera dispositivos da Lei n. ${ }^{\circ}$ 6.019, de 3 de janeiro de 1974, que dispõe sobre o trabalho temporário nas empresas urbanas e dá outras providências; e dispõe sobre as relações de trabalho na empresa de prestação de serviços a terceiros. Disponível em: http://www.planalto.gov.br/ccivil_03/_ato2015-2018/2017/lei/L13429.htm. Acesso em: 23 out. 2019.

BRASIL. Lei n. ${ }^{\circ} 13.467$, de 13 de julho de 2017b. Altera a Consolidação das Leis do Trabalho (CLT), aprovada pelo Decreto-Lei $n .^{\circ} 5.452$, de $1^{\circ}$ de maio de 1943, e as Leis n. ${ }^{\circ}$ s 6.019, de 3 de janeiro de 1974, 8.036, de 11 de maio de 1990, e 8.212, de 24 de julho de 1991, a fim de adequar a legislação às novas relações de trabalho. Disponível em: http://www.planalto.gov.br/ccivil_03/_ ato2015-2018/2017/lei/L13467.htm. Acesso em: 23 out. 2019.

BRASIL. Lei $n^{\circ}$ 5.107, de 13 de setembro de 1996. Cria o Fundo de Garantia do Tempo de Serviço, e dá outras providências. Disponível em: http://www.planalto.gov.br/ccivil_03/leis/l5107.htm\#:-:text=LEI\%2ONo\%205.107\%2C\%20 DE\%2013\%2ODE\%2OSETEMBRO\%2ODE\%201966.\&text=Cria\%20o\%20 Fundo\%20de\%20Garantia,Servi\%C3\%A7o\%2C\%20e\%20d\%C3\%A1\%20 outras\%20provid\%C3\%AAncias. Acesso em: 11 out. 2020.

BÔAS, B. V. Um terço da classe A e B pediu auxílio emergencial. Disponível em: https://valor.globo.com/brasil/noticia/2020/06/03/um-terco-da-classe-a-e-b-pediu-auxilio-emergencial.ghtml. Acesso em: 04 de maio de 2020.

CAIXA ECONÔMICA FEDERAL (CEF). Auxílio emergencial do Governo Federal. Disponível em: https://auxilio.caixa.gov.br/inicio. Acesso em: 03 maio 2020.

CONFEDERAÇÃO NACIONAL DO COMÉRCIO (CNC). Pesquisa de endividamento e inadimplência do consumidor (PEIC). Efeito coronavírus: número de brasileiros endividados bate novo recorde em abril. Disponível 
em: Disponível em: <http://cnc.org.br/editorias/economia/noticias/efeito-coronavirus-numero-de-brasileirosendividados-bate-novo-recordes. Acesso em: 03 maio 2020.

CHUANG. Social contagion: microbiological class war in China. Disponível em: http://chuangcn.org/2020/02/social-contagion/. Acesso em: 15 mar. 2020.

FEDERAÇÃO DAS INDÚSTRIAS DO ESTADO DE SÃO PAULO. Livre para crescer: proposta para um Brasil moderno. FIESP, 1990.

FILGUEIRAS, V. A. (Orgs). Reforma Trabalhista no Brasil: promessas e realidade. Campinas: Curt Nimuendajú, 2019.

FERNANDES, F. Capitalismo Dependente e Classes Sociais na América Latina. São Paulo: Global, 2009.

GORENDER, J. A escravidão reabilitada. São Paulo: Expressão Popular/Fundação Perseu Abramo, 2016.

HAYS, J. N. Epidemics and pandemics: their impacts on Human History. Austin, Texas: Fundação Kahle, 2005.

HABERT, N. A década de 70. São Paulo: Editora Ática. 1992.

HILLESHEIM, J. Conciliação Trabalhista: ofensiva sobre os direitos dos trabaIhadores na periferia do capitalismo. Rio de Janeiro: Lumen Juris, 2016.

INSTITUTO BRASILEIRO DE GEOGRAFIA E ESTATÍSTICA (IBGE). Pesquisa Nacional por Amostra de Domicilios Contínua - PNAD contínua. 2019. Disponivel em: https://www.ibge.gov.br/estatisticas/sociais/trabalho/17270-pnad-continua.html?edicao=27258\&t=sobre. Acesso em: 12 dez 2020.

INSTITUTO BRASILEIRO DE GEOGRAFIA E ESTATÍSTICA (IBGE). Pesquisa Nacional por Amostra de Domicílios Contínua - PNAD contínua. 2020. Disponível em: https://www.ibge.gov.br/estatisticas/sociais/ trabalho/17270-pnadcontinua.html?edicao=27258\&t=sobre. Acesso em: 07 maio 2020.

KATZ, C. Singularidades da América Latina. In: América Latina no limiar do século XXI: temas em debate. Florianópolis: Insular, 2012.

KOWARICK, L. Trabalho e vadiagem: a origem do trabalho livre no Brasil. São Paulo: Editora 34, 2019.

LARA, R. Pandemia e capital: as repercussões da Covid-19 na reprodução social. Libertas. V. 20 n. 01, 2020. 
LARA, R.; SILVA, M. A. Ditadura civil-militar de 1964: os impactos de longa duração nos direitos trabalhistas e sociais no Brasil. Serviço Social e Sociedade. São Paulo, n. 122, p. 275-293, abr./jun. 2015.

MARINHO, Rogério. Modernização das Leis Trabalhistas: o Brasil pronto para o futuro. Petrópolis: De Petrus Editora, 2018.

MATTEI, L.; HEINEN, V. L. Impactos da crise da Covid-19 sobre o mercado de trabalho brasileiro. Texto para Discussão. Núcleo de Estudos de Economia Catarinense - NECAT. Florianópolis, 2020.

MAZIEIRO, G. Guedes: vamos usar recurso público com grandes empresas e ganhar dinheiro. Disponível em: ttps://noticias.uol.com.br/politica/ultimas-noticias/2020/05/22/guedes-vamos-usar-recurso-publico-com-grandes-empresas-e-ganhar-dinheiro.htm. Acesso em: 04 junho 2020.

MORONTE, E. A. A pandemia do novo coronavírus e o impacto na saúde mental dos trabalhadores e trabalhadoras. In: AUGUSTO, C.B; SANTOS, R.D. Pandemias e pandemônio no Brasil. São Paulo: Tirant lo Banch, 2020.

NABUCO, J. O abolicionista. São Paulo: Nova Fronteira, 2000.

ORGANIZAÇÃO INTERNACIONAL DO TRABALHO (OIT). COmo o COVID-19 afetará o mundo do trabalho? Disponível em: https://www.ilo.org/brasilia/ noticias/WCMS_740753/lang--pt/index.htm. Acesso em: 01 maio 2020.

ORGANIZACIÓN INTERNACIONAL DEL TRABAJO (OIT) / COMISIÓN ECONÓMICA PARA AMÉRICA LATINA Y EL CARIBE (CEPAL). Coyuntura Laboral en América Latina y el Caribe. El trabajo en tiempos de pandemia: desafíos frente a la enfermedad por coronavirus (COVID-19). Disponível em: https://www.ilo. org/santiago/publicaciones/coyuntura-laboral-am\%C3\%A9rica-latina-caribe/WCMS_745573/lang--es/index.htm. Acesso em: 03 Jun 2020.

ORGANIZAÇÃO PAN-AMERICANA DE SAÚDE (OPAS); ORGANIZAÇÃO MUNDIAL DA SAÚDE (OMS). Folha informativa - COVID-19 (doença causada pelo novo coronavírus). Disponível em: https://www.paho.org/bra/ index.php?option=com_content $\&$ view=article\&id=6101: covid19\&ltemid $=875$. Acesso em: 01 Jun. 2020.

PAIM; C. S.; ALONSO, W. J. Pandemias, saúde global e escolhas pessoais. Alfenas: Cria Editora, 2020.

PARANHOS, A. O roubo da fala: origens da ideologia do trabalhismo no Brasil. São Paulo: Boitempo, 2007. 
LUXEMBURGO, R. Texto escolhidos. Vomume I. São Paulo: Editora Unesp, 2011. RYDER, Guy. A COVID-19 pôs em evidência a fragilidade de nossas economias. Beasília: OIT, 2020. Disponivel em: https://www.ilo.org/brasilia/noticias/WCMS_740358/lang--pt/index.htm. Acesso em: 17 jun. 2020.

WALLACE, R. Big farms make big flu: dispatches on infectious disease, agribusiness, and the nature of science. New York: Monthly Review Press, 2016.

\section{Notas}

1 Este artigo é produto de estudos realizados no âmbito de duas pesquisas desenvolvidas pelos autores sobre a temática do trabalho: A ideologia da modernização trabalhista no Brasil e As novas bases legais das relações trabalhistas: um estudo de convenções e acordos coletivos de trabalho celebrados em Santa Catarina a partir de 2017. Ambas as pesquisas são realizadas junto ao Núcleo de Estudos e Pesquisas: Trabalho, Questão Social e América Latina, vinculado ao Programa de Pós-Graduação em Serviço Social da Universidade Federal de Santa Catarina.

2 Doutor em Serviço Social. Professor do Departamento de Serviço Social da Universidade Federal de Santa Catarina, Florianópolis, Santa Catarina, Brasil. Orcid: https://orcid.org/0000-0003-1631-8227. E-mail: ricardolarauf@gmail.com

3 Doutor em Serviço Social. Professor do Departamento de Serviço Social da Universidade Federal de Santa Catarina, Florianópolis, Santa Catarina, Brasil. Orcid: https://orcid.org/0000-0002-2798-6418. E-mail: jaime.h@ufsc.br

4 Retomamos aqui argumentos que desenvolvemos originalmente no artigo: LARA, R. Pandemia e capital: as repercussões da Covid-19 na reprodução social. Publicado na Revista Libertas, v. 20 n. 01 (2020).

5 Reproduzimos as explicações de Paim e Alonso sobre as patogêneses e suas relações com as fazendas de criação intensiva de animais para alimentação humana: "Há muitos tipos de vírus influenza circulando em animais silvestres, a maioria aves aquáticas. Sua transmissão para seres humanos a partir dessas espécies não é uma tarefa trivial. Muitas mutações essenciais são necessárias para que vírus que se reproduzem no sistema digestivo de aves, e que são transportados pela água, possam efetivamente ser transmitidos pelo ar e infectar o sistema respiratório humano. As condições perfeitas para a seleção e propagação das mutações que possibilitaram a contaminação e propagação eficiente nos seres humanos estão presentes nos hospedeiros intermediários entre as aves aquáticas e os seres humanos: as galinhas e porcos que criamos para consumo. A alta densidade e grande número de animais mantidos em fazendas de criação intensiva, onde é produzida a maior parte da carne de frango e de porco vendida para a população, permitiu a mistura de diferentes cepas de influenza aviária e a combinação 
do seu material genético (um processo chamado 'mudança antigênica'), o que repetidamente tem levado ao surgimento de vírus que também podem infectar humanos. Os porcos são especialmente aptos como hospedeiros intermediários destes vírus, já que seu trato respiratório superior contém receptores tanto para o vírus da influenza aviária (SA-alpha-2,3) quanto para o vírus suíno/humano (SA-alpha-2,6). Sistemas intensivos de criação de animais, também conhecidos como fazendas industriais, criaram o ambiente perfeito para o surgimento de cepas virais altamente patogênicas, junto com o meio ideal de infecção de seres humanos" (PAIM e ALONSO, 2020, p. 22).

6 Entendemos que a Lei $n^{\circ}$ 13.467, de 13 de julho de 2017 em muito materializa a contrarreforma em comento. Contudo, outras normativas, como a Lei $n^{\circ} 13.429$, de 31 de março de 2017 (que autorizou a terceirização plena), bem como um conjunto de normativas editado e revisto no período, além da uniformização de jurisprudências (determinando a forma de interpretar a lei trabalhista) ou o cancelamento de muitas outras, constituem o que, aqui, entendemos como contrarreforma laboral a partir de 2017 no Brasil.

7 Joaquim Nabuco (2000, p. 156), em 1883, enquanto representante do movimento abolicionista, argumentava em favor da nova concepção de trabalho que se pretendia para a nação brasileira: "Não há dúvidas de que o trabalho livre é mais econômico, mais inteligente, mais útil a terra, benéfico ao distrito onde ele será encravado, mais próprio para gerar indústrias, civilizar o país, e elevar o nível de todo o povo." Como também idealizava o imigrante que substituiria o escravo: "O trabalho livre, dissipando os últimos vestígios da escravidão, abrirá o nosso país à imigração europeia" (NABUCO, 2000, p. 160).

8 Os capitalistas agrários e industriais criaram o exército de reserva à custa da imigração europeia e asiática nas regiões de forte dinamismo econômico e fizeram dos negros uma reserva inesgotável de força de trabalho (GORENDER, 2016).

9 Rosa Luxemburgo alerta sobre a importância da democracia para a classe trabaIhadora realizar avanços e ganhar campo no processo de organização da classe: "Se a democracia se tornou parcialmente supérflua e em parte um obstáculo para a burguesia, inversamente, para a classe trabalhadora, ela é necessária e indispensável. Primeiro, ela é necessária, pois cria formas políticas (auto-organização, direito de voto e similares) que servirão como pontos de partida e de apoio ao proletariado durante sua remodelagem da sociedade burguesa. Segundo, é indispensável, pois apenas nela, na luta pela democracia, no exercício de seus direitos, é que o proletariado pode chegar à consciência de seus interesses de classe e de suas tarefas históricas" (LUXEMBURGO, 2011, p. 73).

10 A inserção do Brasil na condição de País com mercado de trabalho urbano e industrializado nos anos de 1930 ocorreu por meio de uma modernização controlada de fora. A inovação do Brasil na época “incrusta-se em uma re- 
alidade socioeconômica que não se transformou ou que só se transformou superficialmente, já que a degradação material e moral do trabalho persiste e com ela o despotismo nas relações humanas, o privilegiamento das classes possuidoras, a superconcentração de renda, do prestígio social e do poder, a modernização controlada de fora, o crescimento econômico dependente etc [...] Incapaz de provocar uma revolução urbana - como foi incapaz de produzir uma revolução agrícola - o capitalismo em questão faz com que a história social do campo se reproduza na evolução das grandes metrópoles e das cidades" (FERNANDES, 2009, p. 49).

11 As reformas sociais necessárias, em muitos casos, foram anuladas, conforme recorda Fernandes: "A ordem social da sociedade de classes dependente e subdesenvolvida desgasta as 'massas trabalhadoras', a 'gente pobre' e as 'classes operárias', reduzindo a quase nada sua potencialidades de canalizar institucionalmente seus anseios de reforma social ou de mudança social progressiva" (FERNANDES, 2009, p. 85).

12 As contrarrevoluções estiveram presentes e ainda hoje estão na América Latina, com forte apoio das instituições norte-americanas. De acordo com Fernandes: "O que torna a hegemonia dos Estados Unidos entre as nações latino-americanas uma força incontrolável e perigosa é a presente concepção norte-americana de segurança, fronteira econômica e ação conjunta contra mudanças radicais ou revolucionárias nos países vizinhos. Essa concepção implica, na prática, a incorporação desses países ao espaço econômico e sociocultural dos Estados Unidos, por meios organizados institucionalmente. [...] A empresa corporativa é a mais visível dessas instituições; mas as menos visíveis são talvez ainda mais prejudiciais. Elas abrangem instituições oficiais, semioficiais ou privadas, encarregadas de conduzir a política de controle global das finanças, da educação, da pesquisa científica, da inovação tecnológica, dos meios de comunicação de massa, do emprego extranacional das políticas, das forças armadas e mesmo dos governos" (FERNANDES, 2009).

13 O livro da Federação das Indústrias do Estado de São Paulo (FIESP), Livre para crescer: proposta para um Brasil moderno (1990), é o maior exemplo da modernização trabalhista pretendida. Livro que foi elaborado para oferecer parâmetros à economia brasileira durante as crises de 1980 e 1990. Os argumentos antecipam e apresentam a posição da burguesia industrial brasileira a favor das "reformas" e "modernizações" implementadas no Brasil recentemente. Dentre as reformas e modernizações pretendidas no documento da FIESP, destaca-se: as privatizações; a reforma da previdência, a reforma das legislações trabalhistas (ênfase na livre negociação entre capital e trabalho); inserção subordinada do Brasil na economia internacional; abertura ao capital internacional (crescimento do IED); desestruturação completa do movimento sindical; recomendação para que a inserção internacional do Brasil fosse feita pela revalorização da agricultora de exportação. Para fins de ilustração, citamos o que se pensava 
sobre os direitos sociais: "Isso é difícil de transmitir, mas será necessário enfatizar que todos (os trabalhadores) terão que trabalhar mais horas. Necessitaremos de uma reforma constitucional no capítulo dos direitos sociais. Isso só será possível se o medo for bem conscientizado pelo povo e, em especial, pela classe média. Será facilitado ainda pelo uso adequado da popularidade temporária do presidente vitorioso" (FIESP, 1990, p. 258).

14 Esses e outros fundamentos usados pelo empresariado nacional para defender a necessidade de uma ampla "reforma trabalhista" podem ser encontrados em: HILLESHEIM, Jaime. Conciliação Trabalhista: ofensiva sobre os direitos dos trabalhadores na periferia do capitalismo. Rio de Janeiro: Lumen Juris, 2016, 417 p.

15 De acordo com Rogério Marinho, relator da "reforma trabalhista": "A modernização das leis do trabalho teve dois objetivos principais: primeiro, ajudar o Brasil a superar a maior crise de nossa história, herdada por erros cometidos de governos passados, gerando empregos e formalizando o trabalho. Segundo, reformar uma lei que se mostrou anacrônica, desatualizada, e que foi feita para um passado distante; um Brasil que não existe mais" (MARINHO, 2018, p. 44).

16 Rogério Marinho, que vive de convicções e falsa consciência, teve todas as suas perspectivas para o mercado de trabalho contrariadas diante dos dados. Os anos de 2018 e 2019 massacraram suas projeções. Observem suas convicções que se expressam como falsa consciência, mas mesmo assim não deixaram de operar e intervir em defesa da burguesia: "Escudada no mantra da proteção ao emprego, o que vemos, na maioria das vezes, é a antiga legislação gerando injustiças, estimulando o desemprego e a informalidade. Tivemos, assim, plena convicção de que a reforma haveria de contribuir para gerar mais empregos formais e para movimentar a economia, sem compreender os direitos tão duramente alcançados pelos trabalhadores" (MARINHO, 2018, p. 22).

17 O Auxílio Emergencial foi um benefício destinado aos trabalhadores informais, microempreendedores individuais (MEI), autônomos e desempregados. O benefício no valor de $\mathrm{R} \$ 600,00$ foi pago para até duas pessoas da mesma família. Para as famílias em que a mulher fosse a única responsável pelas despesas da casa, o valor pago mensalmente seria de $\mathrm{R} \$ 1.200,00$. Até final do mês de maio de 2020 foram solicitados aproximadamente 97 milhões de auxílios emergências, desses 57,9 milhões de brasileiros foram considerados aptos. O valor total do repasse foi de $\mathrm{R} \$ 74,6$ bilhões (incluindo a primeira e a segunda parcela) (BÔAS, 2020). Desse total, 19,2 milhões de pessoas estavam vinculados ao Programa Bolsa Família e 10,5 milhões estavam inscritas no Cadastro Único do governo federal. O Auxílio Emergencial foi aprovado pelo Congresso Nacional e consolidado na Lei $n^{\circ} 13.982$, de 28 de março de 2020, que foi regulamentada pelo Decreto ${ }^{\circ}$ 10.316, de 7 de abril de 2020, dia em que começaram os primeiros pagamentos (CAIXA ECONÔMICA FEDERAL, 2020). 
18 As palavras de Paulo Guedes na fatídica reunião ministerial são emblemáticas para exemplificar como o atual governo federal apoia as microempresas: "Nós vamos botar dinheiro, e vai dar certo e nós vamos ganhar dinheiro. Nós vamos ganhar dinheiro usando recursos públicos para salvar grandes companhias. Agora, nós vamos perder dinheiro salvando empresas pequenininhas" (MAZIEIRO, 2020).

19 Além disso, o Distrito Federal recebeu 154,6 milhões de reais. Dados disponíveis em: http://www12.senado.leg.br/noticias/materias/2020/05/04/veja-quanto-cada-estado-e-municipio-recebera-no-programa-federativo-de-enfrentamento-ao-coronavirus. Acesso em: 15 jun. 2020.

20 Dados disponíveis em: https://bityli.com/pkQUT

21 São os trabalhadores em situação de risco de vida. Parte desses trabalhadores continuaram suas jornadas, de maneira presencial, "porque desenvolviam serviços essenciais, como aqueles da área da saúde, da segurança pública, venda de alimentos, em farmácias, no tratamento de água, no fornecimento de energia elétrica, na coleta de resíduos urbanos, dentre tantos outros" (MORONTE, 2020, 221).

22 A Organização Internacional do Trabalho (OIT), por meio do seu diretor-geral Guy Ryder, considera que o "[...] teletrabalho oferece novas oportunidades para os trabalhadores continuarem em atividade e os empregadores seguirem com os negócios durante a crise. No entanto, os trabalhadores devem ser capazes de negociar esses arranjos a fim de manter o equilíbrio com outras responsabilidades, como cuidar dos filhos, de doentes ou idosos e, é claro, deles próprios" (RYDER, 2020, p. 3).

23 "A manutenção de um estado de sofrimento relacionado ao trabalho leva, muitas vezes, ao desencadeamento dos chamados transtornos mentais, como os chamados transtornos do humor (ou afetivos) e os transtornos de ansiedade. Dentro desse grupo estão as já conhecidas situações de depressão, transtornos da ansiedade generalizada, do estresse pós-traumático, burn out (esgotamento profissional), suicídios" (MORONTE, 2020, 225).

24 Informações sistematizadas a partir da base de dados do IBGE estão disponíveis em: https://g1.globo.com/economia/noticia/2019/06/26/em-meio-a-crise-mercado-de-educacao-e-o-que-mais-cresce-em-numero-de-empresas-no-brasil-diz-ibge.ghtml. Acesso em: 15 ju. 2010.

25 Disponivel em: https://www.ilo.org/brasilia/noticias/WCMS_740030/lang--pt/ index.htm. Acesso em: 17 jun. 2020. 


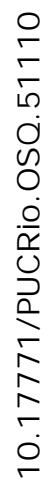

용 